the largest, but also they alone, among all the giant statues of Easter Island, have not been pulled down. Small stone images are scarce, and differ widely in style from the statues; but they are probably ancient. The heads of many of the statues once bore a big cylinder made of red vesicular tuff as a headdress. These range from $1.2 \mathrm{~m}$. to $2 \mathrm{~m}$. in height, and from $1.6 \mathrm{~m}$. to $2.7 \mathrm{~m}$. in diameter. Some had a knob or boss at the top. A slight concavity at the bottom fitted on the head of the statue. It is thought they were a crude attempt to ornament the statues with a structure similar to the top-knot.

The carving of human images from wood and less often from stone is one of the culture traits which distinguish eastern and marginal Polynesia from western Polynesia, where carving of human figures is less developed. Large stone images are carved only in the Marquesas, Raivavae, and Easter Island. Elsewhere in Polynesia wood carving preceded stone carving. The first immigrants to Easter Island probably came from eastern Polynesia, and were there acquainted with earving human figures from wood.

In the religious beliefs the bird-man cult held a most prominent place until the second half of the nineteenth century. As reconstructed from secondhand information it has no parallel in the rest of Polynesia. Though incarnation of gods in animals is a fundamental character in Polynesian religions, nowhere else do open competitions result in the election of a sacred man.

The tablets of the Rongarongo man - the famous wooden tablets covered with hieroglyphs-had associated with them sacred chants, which were sung by learned men or bards. Comparative study suggests that they are not so much inscriptions of the words of the chants as mnemonic. They are a puzzle to science, and the most complicated problem of Easter Island culture. Some tablets dealt with ceremonies, others were parts of ceremonies themselves. They were never read, but were used during chanting. No methodical analysis of the siript has as yet been made. It is not phonetic or syllabic, but it may be a form of pictography. There is no doubt that the signs are symbolic and not decorative.

Parallels to the Easter Island tablets are found in the mnemonic devices of the Marquesas, which consist of a cylindrical bundle woven of coconut fibre, from which hang knotted cords. This bundle is often shaped like a human figure, and is supposed to contain the story of the gods. Other truly analogous mnemonic devices were developed in the Cook Islands, Tuamotus, the Society Islands, etc.

The mystery of Easter Island rests on the assumption that the culture of the island was too elaborate to have been invented by the inhabitants found there by the first European visitors. It was assumed that the monuments of the island were the expression of a civilization which had been destroyed either by a natural disaster or by invasion. It has been assumed also that the Polynesians represent a second wave of invasion; but of any theories of the origin of the original inhabitants the only one worthy of scientific consideration is that they were Melanesians. The parallels, adduced in support, however, are vague and indefinite.

As the result of the careful and exhaustive investigations by the Franco-Belgian expedition of the ethnological data now available, including material culture, past and present social structure, and religious belief, it is concluded that Eister Island was occupied by a single wave of immigrants belonging to the Polynesian race. Exch region of Polynesia stressed and perfected an aspect of its culture-the Marquesas tattooing and the Maoris wood carving, and jade ornaments; and so also Euster Island camo to develop giant statues without the interpolation of a sunken continent or a Melanesian invasion. Faster Island, in fact, is a local Polynesian culture which developed from an archaic and undifferentiated Polynesian civilization.

\title{
FLIGHT AND HABITS OF THE HUMMINGBIRD
}

$\mathrm{S}^{\mathrm{o}}$ METHING close to perfection in flight has been achieved by the tiny hummingbird, the small but relatively powerful wings of which make possible speeds of close to fifty miles an hour and ability to manouvre in the air probably superior to that of any other flying creature. This is explained by Dr. Winsor M. Tyler in a bulletin recently issued by the Smithsonian Institution, in which are described the habits of the familiar ruby-throated hummingbird, the only species ever encountered in the Eastern United States.

The wing beats sometimes are at a rate of seventyfive a second. The bird can take off from a perch in about seven-hundredths of a second. It can remain almost still in the air with about fifty-five wing strokes a second.

Perhaps the hummingbird's greatest achievement, however, is its ability to fly backward. This has often been reported and as often questioned as impossible; but recent photographic technique has shown that the reverse flight is an actuality. This is explained as follows :
"In backing away from a flower or feeding tube the hummingbird stands almost vertically in the air with its tail pointing downward and a little forward. In this pose its wings beat horizontally, and what would be the downward half of each complete wing stroke if the bird's axis were parallel to the ground forces the air forward, away from the bird's breast in its upright position, and drives the bird backward. Then, on the return half-stroke, the whole wing is rotated at the shoulder joint so that its upper surface strikes the air, and, driving it downward, balances the pull of gravity."

Other sidelights on this creature's ways of life are explained by the author. The hummingbird's spring migration northward keeps pace with the opening of its favourite flowers. Males and females usually migrate in separate groups. In fact, they remain apart most of the time, except for brief mating periods. The nest is a model of bird artistry, lined with soft plant down and covered on the outside with bits of lichen. It is usually entirely the work of the female. 
The newly hatched bird is no bigger than a pea and entirely naked. The young probably are born blind. Growth is very rapid, and in less than two weeks the young birds are almost as big as their parents and able to leave the nest.

The hummingbird sips the nectar from blossoms, but a good part of its food consists of insects. Presumably it was originally exclusively an insect eater, specializing on those types likely to be found around blossoms. In this environment the bird has aequired an unappeasable taste for sweets. A single individual has been observed to devour two teaspoonfuls of sugar daily. A human being with a comparable capacity would devour about fifty pounds.

They show a strong preference for red flowers. This, the author believes, is not due to the attractiveness of the colour per se but to the fact that it is always the most striking against a green background.
Hummingbirds often seem to be nervous and irritable. They are intolerant both to each other and to other birds. In spite of their smallness they will attack much larger birds which invade their neighbourhood, relying on their marvellous dexterity of flight to win the conflicts. The special form of attack against a larger bird is a form of 'dive bombing'.

The song is high-pitched and has a "petulant" quality, reflecting the bird's irritable nature. Sometimes the notes are "angry-sounding, mouse-like squeals".

Because of its tiny size the hummingbird meets perils unknown to other birds. There are instances recorded where it has been caught in spider webs. It may become impaled on thorns or stuck to thistles or milkweeds. One instance is cited in which a bird was attacked and destroyed by a dragonfly.

\title{
'ISLAND' FAUNAS ON THE MEXICAN PLATEAU*
}

\author{
Prof. Edward H. TAYlor, \\ UnIVERSITY OF KANSAS
}

$\mathrm{A}$ NIMAL life of Mexico is greatly diversified, and may be primarily divided into the lowland types and highland types. The lowland animals are largely an influx from Central America, after the union of Mexico and Central America. The highland fauna is itself extremely diversified. Considering primarily the herpetological faunas, very few species, if any, have spread over the entire highlands. A great many of the species appear to be distributed in groups occupying very limited areas-much like the distribution of animals in a group of islands. Thus south of the Balsas River there is an area that can boast of 64 species-some 22 snakes, 20 frogs and toads, 22 lizards, not to be found elsewhere in the world; and a total absence of salamanders.

To the east a distance of perhaps two hundred miles in the higher part of the adjoining State of Oaxaca is another 'island', perhaps half as large as the preceding, that has 31 species of reptiles and amphibians not known elsewhere-including 7 salamanders, 10 snakes, 9 lizards and 5 frogs. The exploration of this 'island' has scarcely begun.

The highland region about the City of Mexico and to the east, including the great volcanoes of Orizaba and Popocatepetl, the highest, coldest part of the plateau, has some 25 amphibians and reptiles not known elsewhere, including 5 salamanders, 10 snakes, 10 lizards, and 8 frogs and toads. Just north of this plateau cap is an area which includes much of the State of Hidalgo, which has some 30 species that are not known elsewhere in the world, and still is little explored. Farther north around the city of Saltillo is another, similar, but as yet little-explored, area with several species confined to the highlands of this region. Other similar 'islands' occur in the littleexplored western Sierra.

Thus in this highland mass of Mexico these groups total about 280 species of reptiles and amphibians, known from nowhere else in the world, each group

- Substance of a paper read before the Fighth American Scientific Congress held at Washington during May 1940. occupying its own limited area. Moreover, most of these areas are not contiguous with adjacent 'islands', but are usually separated by some distance. In the Rocky Mountains north of New Mexico and Arizona -a territory nearly as great as that of the Mexican highland-there is apparently not a single endemic species of Reptilia or Amphibia that has evolved.

This 'island-like' grouping of the reptiles and amphibians is not due to strongly differentiated physical or environmental factors of rainfall, temperature, etc., that might normally be expected to limit animal groups into faunal districts; it may in some measure reflect altitude; but they are not typical 'fauna regions'. It would appear that this has been due to ancient isolation.

That these island-like conditions of distribution obtain on the Mexican highlands strongly suggests that much of the evolution of Mexican animals took place prior to the uplift of the highlands; that in this region prior to the uplift there existed groups of islands surrounded by shallow seas-an archipelago perhaps similar to the West Indian Islands of to-day, that had been formed by subsidence of a once continuous land mass that had a rather homogeneous fauna.

Evolution continued for long periods, each island isolated from its neighbour changing the original stock as it could. Then with re-elevation the faunas still reflected their individuality by these island-like areas on the highland.

Further study of the faunas points strongly to the presence of two islands where the present peninsula of Lower California exists to-day, and the probability that the upper was joined to the Mexican mainland and separated from California; that the union between Central America and Mexico was not made until long after the uplift of the Mexican highlands ; that the western coast has been sinking in relatively recent times, as shown by close relationships between the faunas of small islands and the mainland along the western coast. 